\title{
ROOT RESORPTION ASSOCIATED WITH ORTHODONTIC TOOTH MOVEMENT: A REVIEW
}

\author{
Vivek Gupta ${ }^{1}$, Yadvinder S. Dhaliwal ${ }^{2}$, Ambika Dhaliwal \\ ${ }^{1}$ Professor \& Head, Department of Orthodontics \& Dentofacial Orthopaedics, National Dental College \& Hospital, Punjab, India \\ ${ }^{2}$ Reader, Department of Orthodontics \& Dentofacial Orthopaedics, National Dental College \& Hospital, Punjab, India \\ ${ }^{3}$ Reader, Department of Oral Medicine \& Radiology, National Dental College \& Hospital, Punjab, India
}

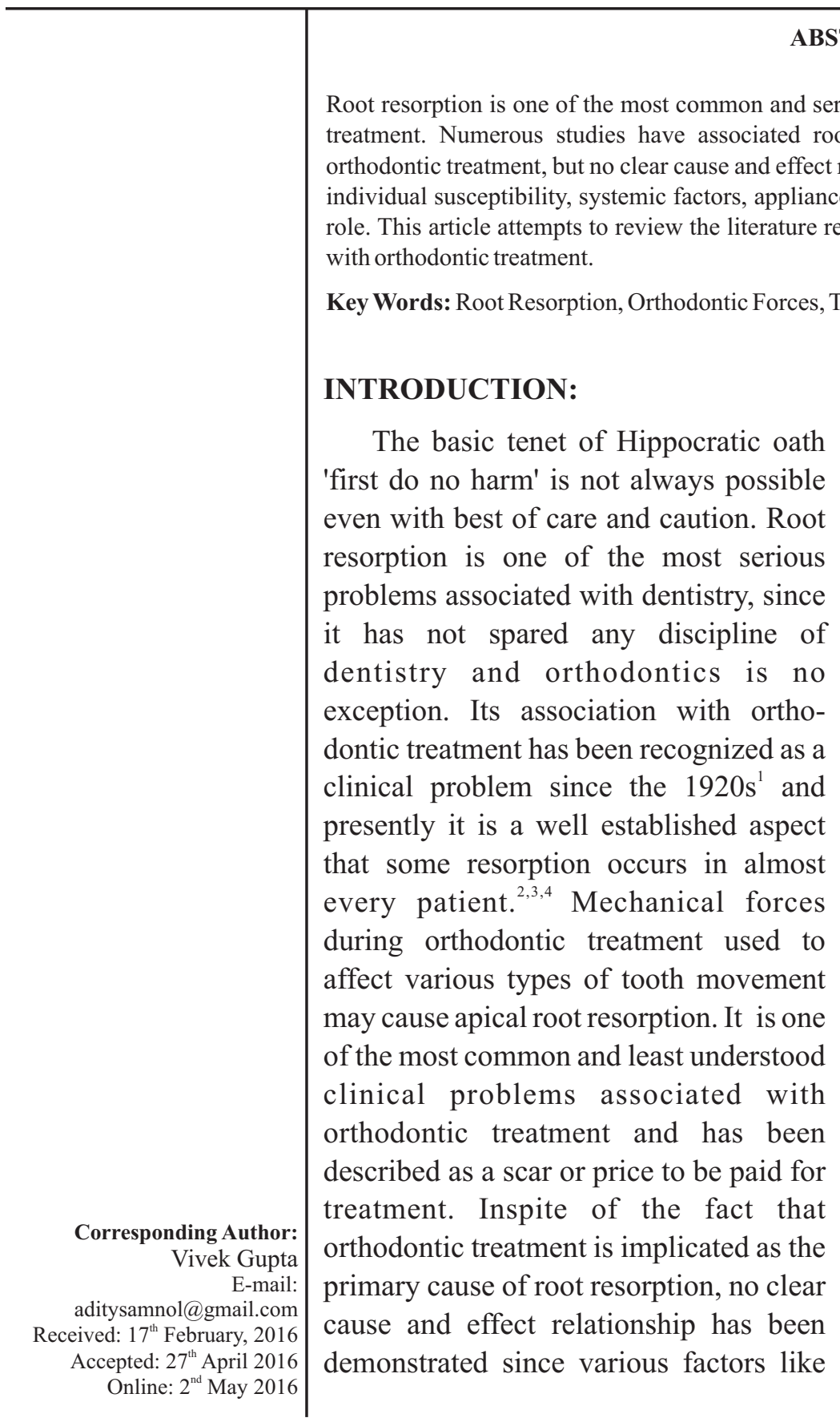

\section{ABSTRACT}

Root resorption is one of the most common and serious side effect commonly associated with orthodontic treatment. Numerous studies have associated root resorption with multiple factors during course of ins been demonstrated .Various factors like

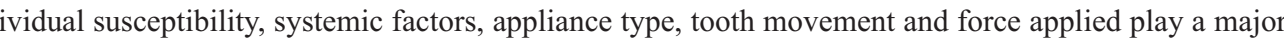
role. This article attempts to review the literature regarding root resorption with various factors associated with orthodontic treatment.

Key Words: Root Resorption, Orthodontic Forces, Translation, Controlled Tipping.

\section{INTRODUCTION:}

'first do no harm' is not always possible even with best of care and caution. Root resorption is one of the most serious problems associated with dentistry, since it has not spared any discipline of dentistry and orthodontics is no exception. Its association with orthodontic treatment has been recognized as a clinical problem since the 1920s and that some resorption occurs in almost every patient. ${ }^{2,3,4}$ Mechanical forces during orthodontic treatment used to affect various types of tooth movement of the most common and least understood clinical problems associated with orthodontic treatment and has been described as a scar or price to be paid for treatment. Inspite of the fact that orthodontic treatment is implicated as the primary cause of root resorption, no clear cause and effect relationship has been individual susceptibility, systemic factor, appliance type, tooth movement and force applied play a major role.

Historical Perespective:

It is often stated that the degree of root damage is a function off the appliance used. Ketcham ${ }^{1}$ (1929) in a radiographic survey to analyse the relation of types of appliances to the incidence and extent of resorption in 500 cases, reported that root resorption occurred much more frequently with the pin and tube appliances than the ribbon brackets. $\mathrm{He}$ further stated that even the plain labial arch of lingual appliance was not entirely free from this criticism. Ketcham stated that immobilisation rather than jiggling has a great deal to do with root resorption. Since fixed appliances puts the teeth out of function and out of exercise, thus disturbing the normal function by their splinting effect, the orthodontic fixed appliances, causes more root resorption.

Linge and Linge 5 (1983) did a systematic comparison of root resorption 
resulting from fixed and removable appliance. They found the fixed appliance caused significantly more apical root resorption than removable appliance. The investigators concluded that while choosing treatment appliance, the risk of resorption should be weighed against appliance efficiency and individual treatment objectives.

There is a fundamental difference in the two common approaches to orthodontic treatment i.e. differential force system of begg mechanics (light wire mechanics) and controlled forces of tweed mechanics (edge wise mechanics). Opponents of begg technique claim that the tipping and subsequent torquing of the upper anterior teeth, so called 'round typing' is harmful to the roots. ${ }^{6}$ Opponents of the edge wise mechanics point to the heavy force of extra oral appliances and rectangular arch wire and subsequent frictional forces to be more detrimental to the roots.

Jenson et.al. $^{7}$ (1999) compared the amount of root resorption after orthodontic treatment between the simplified standard edge wise technique, the edge wise straight wire system and the bio efficient therapy. In this study significantly less root resorption was found in patients treated with bio efficient therapy compared to other two methods. The investigators suggested that the less root resorption with bio efficient therapy is due to the use of triangular single width bracket which increases the interslot distance that consequently allows an increase in the interslot arch wire length and a greater flexibility. In addition bio efficient therapy uses super elastic wires, which produces a more biologic action, with less discomfort to the patient.

It has been reported that cases involving premolar extraction are more subjected to greater degree of root resorption. In a retrospective study ${ }^{8}$ of 1049 cases Marques found a high incidence of root resorption $(14.5 \%)$ at the end of treatment compared to non extraction cases. It is suggested that the greater apical movement in cases of extractions, especially in anteroposterior, direction is the real risk factor for root resorption.

Many studies ${ }^{9-10}$ have been performed to investigate the relationship between the magnitude of applied force and subsequent root resorption since it is believed to be an important factor. Reitan ${ }^{4}(1965)$ has suggested that this is the single most crucial factor in the root resorption. It remains to be determined whether an optimal range of non pathologic orthodontic pressures exist for a particular type of tooth movement, or whether malocclusion treatment is generally associated with some degree of root resorption.

Clinical Overview:

It is commonly believed that too strong a force would cause increase damage to the engaged tissues and subsequent root resorptions. Several studies have found a positive correlation between force magnitude and root resorption. However, some studies have reported a negative correlation between the above two factors. $^{2,4,5}$

It doesn't seem logical however that a small force magnitude would cause a larger degree of root resorption as reported in few studies. It is possible that the normal individual variation may have over shadow the effects of a doubled force magnitude. Another explanation could be that the heavy forces may be too heavy for the optimal tissue reactions to occur close to the tooth surface, resulting in a limited tissue reaction due to compression with tooth movement achieved by undermining bone resorption. This concept would lead to an even more speculative view that a 4-6 times larger forces would move the tooth by undermining resorption in the bone, causing no root resorption at all due to lack of any possibility of root surface reaction as a result of the hyalinization with sterile necrosis of root surface soft tissue.

The duration of force magnitude has been regarded as a more critical factor than the magnitude of force especially in conjunction with long treatment periods. Several investigators have reported an association between the severity of root resorption and duration of applied forces.

Efficacy becomes an important factor during orthodontic treatment since it requires a long treatment period. However, both tooth movement and adverse tissue reactions have to be considered which demand a careful choice of the amount, direction and duration of forces acting on the teeth. In choosing treatment appliances, the risk of root resorption should be 
weighed against the appliance efficiency and the individual treatment objectives. The orthodontic profession critically needs clinical data on the relative efficiencies of different biomechanical strategies of tooth movement so as to foretell which approach would provide the most rapid orthodontic tooth movement with the least damage to the teeth and their supporting structures.

Taking these aspects into account, some very important clinical conclusions can be established regarding various aspects of fixed orthodontic mechanotherapy.

They are:

1. Discontinuos vs continuos force: according to Acar et $\mathrm{al}^{12}$ continuos force proved significantly more root resorption as compared to teeth experiencing discontinuos force. However other studies are yet to reach a certain conclusion regarding this finding.

2. Orthodontic appliances. Comparing root resorption resulting from removable and fixed appliances, it was established that root resorption more often is induced by treating it with fixed appliances. Stuteville has stated that forces caused by removable appliances are more harmful to the roots. ${ }^{13}$ IlanaBrin has studied influence of treatment methods of class Angle II orthodontic malocclusion on teeth roots. The results showed that root resorption was diagnosed more rarely in children who have undergone 2-phase orthodontic treatment first of all with functional removable appliance and later with fixed appliance, than in children, who have undergone orthodontic treatment with fixed orthodontic appliances only. ${ }^{14}$ While assessing the influence of metal and aesthetic brackets on root resorption, it was diagnosed more often in patients treated with aesthetic brackets. This is because treatment with aesthetic brackets lasts longer. ${ }^{15}$ Application of an additional upper utility arch for intrusion of maxillary incisors induces root resorption of maxillary central incisors more often than by treating with straight arch. $^{16}$

3. Intermaxillary elastics: greater root resorption is found on the side of tooth arch where elastics were used. Use of Class III elastics increases root resorption of first mandibular molars distal root. ${ }^{17}$ Some researchers have established that use of intermaxillary Class II elastics and type of orthodontic arch does not have any influence on occurrence of root resorption. ${ }^{18}$

4. Removable thermoplastic/acrylic appliance vs fixed light wire appliance: Barbagallo et $\mathrm{al}^{19}$ compared forces applied with removable thermoplastic appliances (TA) and fixed orthodontic appliances and results showed that the test experiencing orthodontic movement using light forces (25 g) and TA force resulted in similar root resorption cemental loss.

5. Light vs heavy continous forces: four split mouth studies from the same research group by Chan \& Darendilier $^{20}$ compared fixed orthodontic light $(25 \mathrm{~g})$ continuous force with fixed orthodontic heavy $(225 \mathrm{~g})$ continuous force in patients needing premolar extractions to relieve crowding or overjet. It was observed that heavy continous force produce significantly more root resorption than light forces. Ultra microscopic assessment revealed that mean volume of resorption craters was 11.59 times greater in heavy forces group as compared to light forces group.

Barbagallo et $\mathrm{al}^{19}$ also found that heavy force produced significantly more root resorption (9 times) than light force.

Harris et $\mathrm{al}^{20}$ produced intrusive forces \& results showed that volume of root resorption craters after intrusion was directly proportional to the magnitude of the intrusive force.

6. Intrusive vs extrusive forces: Han et $\mathrm{al}^{21}$ found that root resorption from extrusive force was not significantly high. However intrusive forces significantly increase the percentage of resorbed root area.

7. Archwire Sequence: Mandall et $\mathrm{al}^{22}$ compared 3 orthodontic arch wire sequences in terms of patient discomfort, root resorption, and time to working arch wire. All patients were treated with maxillary and mandibular preadjusted edgewise appliances (0.022 in slot) and all arch wires were of same 
manufacturer. The results showed no statistical significant difference between the proportion of patients with and without root resorption between arch wire sequence groups.

8. Effect of treatment pause in patients: Levander et $\mathrm{al}^{23}$ investigated effect of pause in active treatment on teeth that had experienced apical root resorption during the initial 6 month period with same category of fixed appliances. The results clearly showed that the amount of root resorption was significantly less in patients treated with a pause than those treated with continuous forces without a pause.

9. Straight wire vs standard edgewise appliances: Reukers et $\mathrm{al}^{24}$ compared prevalence and severity of root resorption after treatment with a fully programmed edgewise appliance (FPA) and a partly programmed edgewise appliance (PPA). The results exhibited no statistically significant difference in amount of tooth root loss or prevalence of root resorption between the groups.

10. Anomalies of position and the number of teeth. Supposedly, hypodontia increases risk of root resorption. ${ }^{25}$ Impacted teeth may also induce occurrence of root resorption. Third molars are the most commonly impacted teeth, which may cause root resorption of the second molar through the cutting of the third molar, which lacks the place in the tooth arch. ${ }^{26}$ Maxillary canine are the second most commonly impacted teeth; they can induce root resorption of the incisors and first premolars ${ }^{27}$ (Fig. 1). It is recommended annual palpation of the canine regions, dental radiographs before 10 years of age and early extraction of deciduous canines. ${ }^{28}$

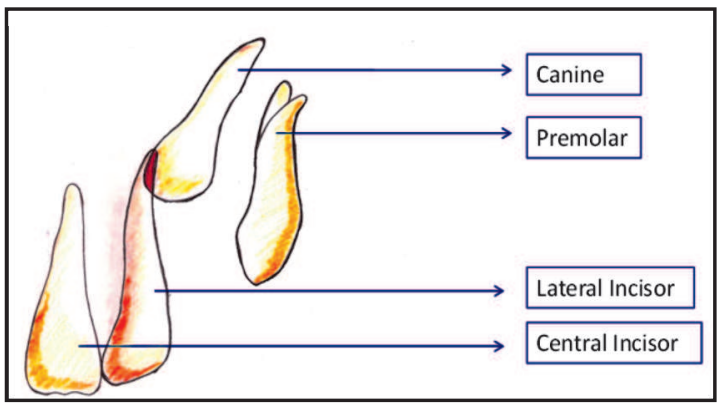

Figure 1: Erupting canine teeth may induce root resorption of the lateral incisors and first premolars
11. Tooth structure. Root resorption most often occurs in the apical part of the root, because forces are concentrated at the root apex because orthodontic tooth movement is never entirely translatory and the fulcrum is usually occlusal to the apical part of the root; periodontal ligaments are situated in different directions in the apical part of the tooth root; the apical third of the root is covered with cellular cemen-tum, whereas the coronary third is covered by non-cellular cementum. Active cellular cementum depends on blood circulation; thus periapicalcementum is more friable and easily injured in the case of trauma. ${ }^{29}$ Most authors have shown that roots with abnormal shape have a higher susceptibility to root resorption. According to the data of Sameshima and Sinclaire, normal and blunt tooth roots are resorbing the least. ${ }^{15}$ Pipetteshaped roots are the most susceptible root form to root resorption. ${ }^{13}$ Short roots have a greater risk for root resorption than average length roots. ${ }^{30}$ It was found that small roots resorbe almost twice more than other root forms. ${ }^{15}$ There are controversial data about initial length of the tooth root and the amount of tooth root resorption. There is an opinion that longer roots are more likely to be resorbed than shorter ones because longer roots are displaced farther for equal torque. ${ }^{31}$ Tooth with longer roots need stronger forces to be moved and that the actual displacement of the root apex is greater during tipping or torquing movements. ${ }^{29}$ It was established that a normal root form of central incisors and wide roots are preventive factors of these teeth roots, decreasing risk of root resorption. ${ }^{32}$ Slightly increased root resorption is characteristic for the tooth with narrower roots. ${ }^{27,32}$

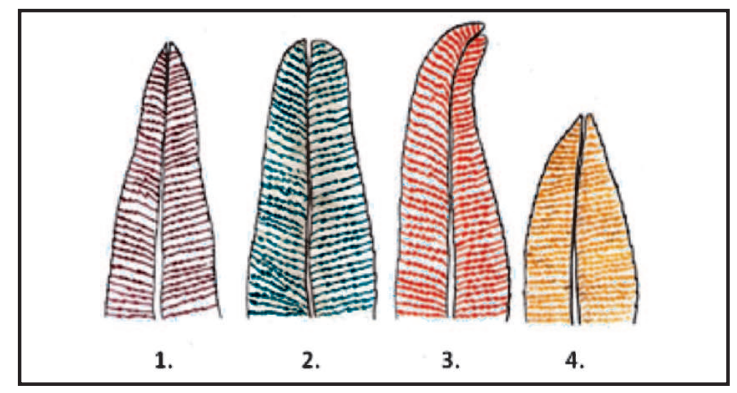

Figure 2. Root Forms

1- pipette-shaped root; 2- blunt root; 3- dilacerated root; 4- short root. 
12. Dental trauma may cause root resorption to the teeth without orthodontic treatment. Orthodontically moved traumatized teeth with previous root resorption are more sensitive to further loss of root material $^{13}$. The teeth can be treated orthodontically three months after the tooth transplantation or replantation. According to the research data, a completely assimilated transplanted tooth reacts to orthodontic force as a normal tooth. ${ }^{25}$

13. For endodontically treated teeth increased and more often root resorption is characteristic during the orthodontic treatment. The hypothesis was raised that endodontically treated teeth are more resistant to root resorption because of increased hardness and density of dentin. ${ }^{25}$ Qualitative endodontic treatment of teeth is very important. When the root canal filling reaches the root apex, resorption doesn't start however in case of a shorter filling a part without the filling resorbe. ${ }^{25}$

14. Alveolar bone density on root resorption is assessed controversially. A part of the studies has es-tablished that the denser is alveolar bone, the more root resorption occur during the orthodontic treatment. According to Reitan, strong continuous force affecting alveolar bone of less density causes the same root resorption as a mild continuous force affecting alveolar bone of higher density. It is more difficult to resorb with orthodontic pressure than bundle bone. Wainwright has stated that bone density determines tooth movement rate but has no relation to the extent of the root resorption. ${ }^{13,29}$ Cementum is harder than alveolar bone and more mineralized, more fibres of periodontal ligaments are inserted into cementum than in alveolar bone, thus osteoclasts have less possibility to injure the cementum layer and induce root resorption. ${ }^{33}$

15. Correlation between malocclusion and tooth root resorption was assessed. According to the data of studies performed by Vander Ahe there is no relation between root resorption and malocclusion. Naphtali Brezniak et al. have stated that dental and skeletal malocclusion induce occurrence of root resorption. No one orthodontic malocclusion is immune to root resorption. ${ }^{25}$ Upon studying tooth root resorption occurring during treatment of Angle II class orthodontic malocclusion, it was established severe ( $>2 \mathrm{~mm}$ ) maxillary incisor root resorption in $4 \%$ of children. ${ }^{14}$ According to the research data of Kaley and Phillips, the patients with Angle III class orthodontic malocclusion experience increased root resorption. ${ }^{31}$

16. Relationship between the change in overjet and severity of root resorption was observed. The greater the overjet during the orthodontic treatment, the greater the root resorption for maxillary anterior teeth ${ }^{18,31}$, because greater tooth movement is necessary in order to decrease overjet. Malocclusion in vertical plane do not influence occurrence of increased root resorption. Increased overbite may correlate with more root resorption of maxillary lateral incisors. It was established that the deeper is overbite, the greater is root resorption of a maxillary permanent first molar distal root and maxillary incisor. ${ }^{29}$

17. Trauma vs no trauma: Brin et $\mathrm{al}^{34}$ showed that incisors with clinical signs of trauma had essentially the same prevalence of moderate to severe Orthodontically induce inflammatory root resorption (OIRR) as those without trauma. Mandall et al reported no evidence of incisor trauma and root resorption. Levander et $\mathrm{al}^{23}$ also showed no statistically significant correlations between root resorption.

Implications for clinical practice:

Evidence clearly points out that comprehensive orthodontic treatment causes increased incidence and severity of root resorption and heavy forces are particularly harmful. As of yet the necessary know how for high quality clinical trials is a limiting factor to reach a definite conclusion but the best practice is using 
light forces for tooth movement.

As new evidence emerges for identifying patients with genetic susceptibility to root resorption, efforts are underway to develop routine diagnostic tests for determining risk and prior probability estimates of the same.

\section{REFERENCES}

1. Ketcham A.H: A progress report of an investigation of apical root resorption of vital permanent teeth. Int J Orthod 1929; $15: 310-328$.

2. DeShields R.W: A study of root resorption in treated Class II division 1 malocclusions. Angle Orthod 1969; 39:231-245.

3. Harry M.R, Sims M.R: Root resorption in bicuspid intrusion: a scanning electron microscope study. Angle Orthod 1982; $52: 235-58$.

4. Reitan K: Intial tissue behaviour during apical root resorption. Angle Orthod 1974; 44:68-82.

5. Linge B.O, Linge L: Apical root resorption in upper anterior teeth. Eur J Orthod 1983; 5:173-83.

6. Stuteville O.H: Injuries caused by orthodontic forces and the ultimate results of these injuries. Int J Orthod Oral Surgery 1938;24:103-17.

7. Jenson G.R.P, Canto G, Martins DR: A radiographic comparison of apical root resorption after orthodontic treatment with 3 different fixed appliance techniques. Am J Orthod Dentofac Orthop 1999; 118:262-67.

8. Marques L.S.: Severe root resorption in orthodontic patients treated with the edgewise method. Prevalence and predictive factors. Am J Orthod Dentofac Orthop 2010; 13:384-388.

9. Vardimon A.D, Graber T.M, Voss L.R, Lenke J: Determinants controlling iatrogenic external root resorption and repair during and after palatal expansion. Angle Orthod 1991; 61:113-22.

10. Reitan K: Biomechanical properties and reaction. In Graber T.M, Swain B.F, editors. Orthodontics: current principles and techniques. St Louis Mosby 1985: 101-92.

11. Stevnik A, Mjor JA: Pulp and dentin reactions to experimental tooth intrusion. Am J Orthod 1970; 57: 370-85.

12. Acar A, Canyurek U, Kocaaga M, Erverdi N: Continous vs.
Discontinuous force application and root resorption. Angle Orthod 1999; 69:159-63.

13. Brezniak N. Root resorption after orthodontic treatment. Part II. Literature review. Am J Orthod Dento facial Orthop 1993; 103:138-46.

14. Brin I. External apical root resorption in Class II malocclusion: A retrospective review of 1-versus 2-phase treatment. Am J Orthod Dento facial Orthop 2003;124:151-6.

15. Nigul K, Jagomagi T. Factors related to apical root resorption of maxillary incisors in orthodontic patients Stomatologija. Baltic Dent Maxillofac J 2006; 8:76-9.

16. Steffen W. A radiographic evaluation of apical root resorption following intrusion therapy: poster. J Dent Oral Med 2007; 9 ( 02): 357

17. Brezniak N. Root resorption after orthodontic treatment. Part II. Literature review. Am J Orthod Dento facial Orthop 1993;103:138-46.

18. Sameshima GT, Sinclair PM. Prediction and prevention root resorption: Part II. Treatment factors. Am J Orthod Dentofacial Orthop 2001;119:511-5.

19. Barbagallo L.J, Jones A.S, Petocz P: Physical properties of root cementum: part 10. Comparison of the effects of invisible removable thermoplastic appliances with light and heavy orthodontic forces on premolar cementum. A microscopic study. Eur J Orthod 2001; 133:218-27.

20. Darendellier M, Chan E: Physical properties of root cementum: part 7. Extent of root resorption under areas of compression and tension. Am J Orthod Dentofac Orthop 2006; 129: 504-10.

21. Han G, Huang S, Von Den Voff J.W: Root resorption after orthodontic intrusion and extrusion: an intraindividual study. Angle Orthod 2005; 75: 912-18.

22. Mandall N, Lowe C, Worthington H: Which orthodontic archwire sequence? A randomized clinical trial. Eur J Orthod 2006; 28: 561-66.

23. Levander E, Malmgren O, Eliasson S: Evaluation of root resorption in relation to two orthodontic treatment regimes. A clinical experimental study. Eur J Orthod 1994; 16: 223-28.

24. Reukers E, Sandernik G: Assesment of apical root resorption using digital reconstruction. Dentomaxillofac Radiol 1998; 29:399-411. 
25. Brezniak N. Orthodontically induced inflammatory root resorption. Part II: The clinical aspects. Angle Orthod 2002;72:180-4.

26. Tabiat-Pour S. Root resorption of a maxillary permanent first molar by an impacted second premolar. Br Dent J 2007; 202:261-2.

27. Savage RR, Kokich VG Sr. Restoration and retention or maxillary anteriors with severe root resorption. Am Dent Assoc 2002;133:67-71.

28. Milberg D. Labially impacted canines causing severe root resorption of maxillary central incisors. Angle Orthod 2006; 76:173-6.

29. Hartsfield J. Genetic factors in external apical root resorption and orthodontic treatment. Crit Rev Oral Biol Med 2004; $15: 115-22$.
30. Travess H. Orthodontics. Part 6: Risks in orthodontic treatment. Br Dent J 2004;196:71-7.

31. Luther F. Teamwork in orthodontics: limiting the risks of root resorption. Br Dent J 2005; 198:407-11.

32. Kook YA, Park S, Sameshima GT. Peg-shaped and small lateral incisors not at higher risk for root resorption. Am J Orthod Dentofacial Orthop 2003;123:253-8.

33. Roberts-Harry D, Sandy J. Orthodontics. Part 11: Orthodontic tooth movement. Br Dent J 2004;196:391-4.

34. Brin I, Tulloch J.F.C, Korulouk L: External apical root resorption in Class II malocclusion: a retrospective review of 1 versus 2 phase treatment. Am J Orthod Dentofac Orthop 2003; 124:15-56. 